\title{
Educating the Professional Engineer of 2020:
}

\section{Dr. Susan L. Murray, Missouri University of Science \& Technology}

Susan L. Murray is a professor of engineering management and systems engineering at Missouri University of Science and Technology. Dr. Murray received her B.S. and Ph.D. in industrial engineering from Texas A\&M University. Her M.S. is also in industrial engineering from the University of Texas-Arlington. She is a professional engineer in Texas. Her research and teaching interests include human systems integration, productivity improvement, human performance, safety, project management, and engineering education. Prior to her academic position, she spent seven years working in industry including two years at NASA's Kennedy Space Center.

\section{Dr. Terri M. Lynch-Caris, Kettering University}

Terri Lynch-Caris, Ph.D., P.E., is an Associate Professor of Industrial \& Manufacturing Engineering (IME) and Director of the Center for Excellence in Teaching and Learning (CETL) at Kettering University in Flint, Michigan. She earned her Ph.D. at the University of Michigan, holds an MS Degree from Purdue University and a BS from Kettering University, formerly GMI-Engineering \& Management Institute. She teaches courses in Work Design, Ergonomics, Statistics and various other Industrial Engineering classes. Her research is in the area of Human Work Design and Environmental Design. 


\title{
Educating the Professional Engineer of 2020: The Changing Licensure Requirements
}

\begin{abstract}
Engineering education programs would be well served to align their curricula and program outcomes to the Fundamentals of Engineering (FE) Exam and Professional Engineer (PE) Exam specifications. These exams are required steps in the process of becoming a licensed engineer in most states. NCEES (the National Council of Examiners for Engineering and Surveying) is a national nonprofit organization dedicated to advancing professional licensure for engineers and surveyors. It develops, administers, and scores these examinations used for engineering licensure. Starting in 2011, NCEES held survey-creation meetings with diverse teams to develop a draft survey containing the subjects in each discipline and establish consensus support. NCEES launched a web-based survey of technical society members, institution report recipients, deans and department heads of all EAC/ABET programs, PE and FE exam committee volunteers, and others; more than 7,000 people completed the survey. Respondents rated the importance of each topic area to indicate how important it is for a new engineer to have minimum competence in that area. Based on these survey results, a set of topics and associated weighting was proposed and approved. Starting in 2014 the various FE exams will contain some overlapping content (e.g., mathematics and engineering economics), but there will no longer be a common breadth portion. Each FE exam, including industrial engineering, will be a freestanding exam. The PE exam specifications have also been revised; the new specifications will be used beginning in 2013.

This paper highlights these recent changes to the discipline-specific content of the industrial engineering (IE) exams and suggests possible resulting curriculum modifications. As the IE profession undergoes changes in its application of traditional principles and adds new areas of focus, it is timely that the FE and PE exam specifications have been revisited to reflect changing priorities within the profession. For academic departments to stay relevant and assist industrial engineering graduates to become PE licensed, modern curriculum should stay closely aligned to the FE and PE exam specifications but not attempt to "teach to the test". The paper concludes with a discussion of how these specifications have been used to assess and update academic curriculum.
\end{abstract}

\section{Background on Professional Licensure through NCEES}

The National Council of Examiners for Engineering and Surveying (NCEES) is a national nonprofit organization dedicated to advancing professional licensure for engineers and surveyors. It develops, administers, and scores the examinations used for engineering and surveying licensure in the United States. It also facilitates professional mobility and promotes uniformity of the U.S. licensure processes through services for its member licensing boards and licensees. These services include the records program, study materials, credentials evaluations, exam administration, and more. 
The NCEES is governed by a set of bylaws under the supervision of a board of directors elected by the Council's member licensing boards. The Council's members are the engineering and surveying licensure boards from all 50 states, the District of Columbia, Guam, Puerto Rico, and the U.S. Virgin Islands. The NCEES Strategic Plan describes several issues that represent challenges to maintaining an effective licensure process. The document, which is periodically updated by the board of directors, specifies goals associated with each of the issues and describes strategies for achieving these goals [NCEES, 2012].

\section{Vision}

The vision of NCEES is to provide leadership in professional licensure of engineers and surveyors through excellence in uniform laws, licensing standards, and professional ethics for the protection of the public health, safety, and welfare and to shape the future of professional licensure.

\section{Mission}

The mission of NCEES is to advance licensure for engineers and surveyors in order to protect the health, safety, and welfare of the public.

This mission is supported through its member boards, board of directors, staff, board administrators, and volunteers by:

- Providing outstanding nationally normed examinations for engineers and surveyors

- Providing uniform model laws and model rules for adoption by the member boards

- Promoting professional ethics among all engineers and surveyors

- Coordinating with domestic and international organizations to advance licensure of all engineers and surveyors

Figure 1. NCEES Vision and Mission [NCEES, 2012]

\section{The Process of Developing Professional Topics}

The NCEES process of re-evaluating professional topics within each discipline is approximately a three-year cycle. The NCEES has the responsibility to gathering together professionals from each discipline to reach consensus at each step of the process. The process begins with surveycreation meetings. Attendees at the meeting represent diverse individuals from representative disciplines with the goal to develop a survey containing the potential exam subjects in each of the engineering disciplines. The survey is reviewed and revised until consensus support is achieved. The most recent survey was web-based to allow global convenience and maximum input. 
Through the leadership of NCEES, the web-based survey was sent to technical society members, institution report recipients, deans and department heads of all EAC/ABETS programs, PE and FE exam committee volunteers, and other discipline professionals. There were more than 7,000 survey responses from interested stakeholders and experts. The goal of the FE exam is to establish minimum competence. Thus, survey respondents rated the importance of each topic area. The rating indicated how important it is for a new engineer to have minimum competence in the specified area. Based on these survey results, a set of topics and associated weighting was proposed and approved.

The next step in creating a new exam is writing a pool of questions for each exam. This will be done be committees of experts in the same manner prior exams have been prepared. In the past, the morning session of the FE was common for all engineers representing the breadth of the engineering profession and the afternoon session contained a depth of topics specific to each discipline. Starting in 2014 discipline-specific FE exams will be freestanding and may contain some overlapping content (e.g., mathematics and engineering economics). However, there will not be a common breadth portion, please see Figure 2 .
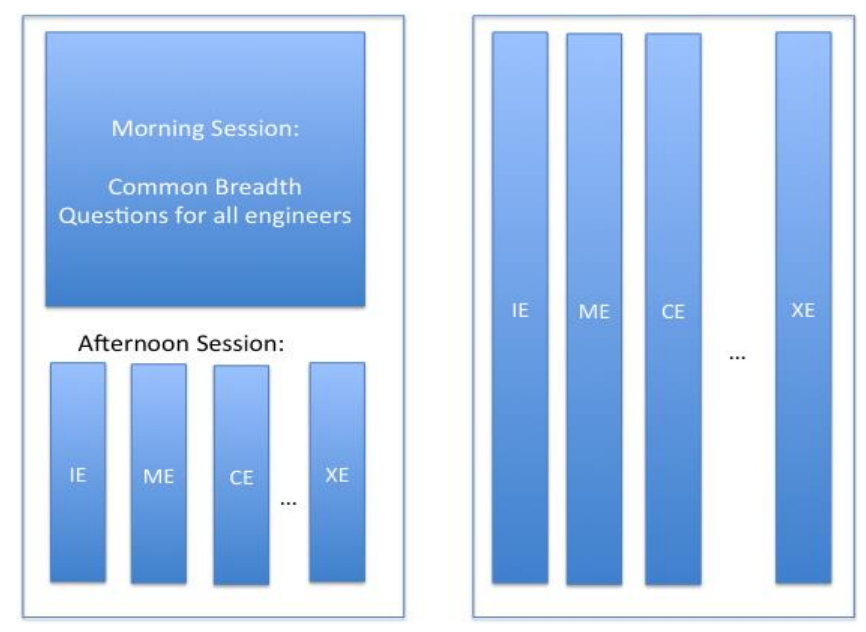

Figure 2. Pre-2014 FE Exam Format (Left) and New 2014 Format (Right)

The final step is for NCEES to administer the exam. In the past, exams were given at pre-defined testing centers across the nation twice per year on designated dates in April and October. In addition to monitoring the testing facilities for possible cheating, this practice attempted to maintain the integrity of the exam by controlling the schedule. A new process planned for 2013 will allow computer based testing (CBT) centers to administer the test more often throughout the year. This will allow expansion of time and location for applicants to take the test. Pre-defined testing centers must follow strict and specific processes including biometric scanning to verify the identity of the test-taker. 


\section{Industrial Engineering Topics}

The major domains and topics for each engineering specific discipline have been reviewed and revised over time. The major domains for the 2014 exam have just been released; they are shown in Figure 3 along with the number of questions in each area. Topics under each of the major domains for the 2014 exam are available on the NCEES website. The one area that was added to IE exam is Systems Engineering. Topics in this area include:

- Requirements analysis

- Systems design

- Human system integration

- Functional analysis and allocation

- Configuration management

- Risk management

- Verification and assurance

- System life cycle engineering

The importance of service systems was also highlighted in the survey results and will likely be covered in greater detail on the exam. The focus on safety was increased, while the priority weight given to some other existing topics were decreased.

\section{IE Major Domains (Number of Questions)}

Mathematics (6-9)

Engineering Sciences (5-8)

Ethics and Professional Practice (5-8)

Engineering Economics (10-15)

Probability and Statistics (10-15)

Modeling and Computations (8-12)

Industrial Management (8-12)

Manufacturing, Production, and Service Systems (8-12)

Facilities and Logistics (8-12)

Human Factors, Ergonomics, and Safety (8-12)

Work Design (8-12)

Quality (8-12)

Systems Engineering (8-12)

Figure 3. New Industrial Engineering FE Exam Topics 


\section{Curriculum Review}

Every academic discipline must review and refresh their curriculum. Specifically, the core curriculum must meet the present needs of industry while preparing the student to adapt to inevitable change. Elective courses allow students greater depth and breadth outside of the core fundamentals. To map the core and elective courses individually to the FE exam topics will allow the analysis of the entire curriculum at a glance. The goal is to be intentional about the discipline and what is taught within each program.

Some faculty members may have unique topics and expertise that is not captured in the FE Exam topic list. Additional domains and/or topics are often added at the discretion of the program. Such additional areas of expertise may offer a uniqueness that sets the program apart from others. However, if there is more uniqueness than foundational topics, the program may consider changing the title of the program to something that more appropriately fits their unique offerings.

The first step in the review is to identify all core and elective courses that reside within the department. It may be appropriate to include core courses from other departments when they are prerequisite to the discipline-specific knowledge core. For example, a first course in probability and statistics may be part of the general education program taken by all engineering students. Industrial engineering students, however, must build on this foundational knowledge to consider more advanced statistics for designing experiments and applying quality control techniques. Thus, the basic probability and statistics course must be included in the curriculum review in order to apply such prerequisite knowledge to follow-on courses.

Consider the topic coverage in the core courses as the working knowledge that all students will have at graduation. The elective courses contribute to the program as opportunities for all and should enhance the personalized educational experience for those students who are interested in more depth in a specific area. The initial review can be as simple as whether the topic is covered in the class, an example is shown in Figure 4. A more formal review can consider the depth to which a topic is address. Blooms Modified Taxonomy (Anderson \& Krathwohl, 2001) uses verbs: remembering, understanding, applying, analyzing, evaluating, and creating for levels of learning objectives. For example the instructor of a facility layout class may expect students to reach the understanding level of manual material handling, while an ergonomics instructor would seek a higher level such as analyzing or evaluating.

Learning objectives that are in a course but not on the list of topics from the FE exam should be captured. An example of this is shown at the bottom of Figure 4. Four subtopics that are included in this particular industrial engineering department's curriculum than are not addressed in the FE exam requirements are listed. Upon review the faculty decided to continue including these topics. Two were more in-depth coverage of the topic and two were that the students would have experience using software in the course to solve problems. Using particular computer software is not a fundamental knowledge requirement but was considered a useful skill. 


\begin{tabular}{|c|c|c|c|c|c|c|c|c|c|c|c|c|c|c|c|}
\hline & FE Exam Topics - 2009/2013 & & & & & & & & & & & & & & \\
\hline & & $\bar{\Sigma}$ & $\stackrel{N}{\frac{N}{d}}$ & $\stackrel{5}{\stackrel{N}{N}}$ & 棺 & 苞 & 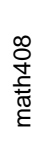 & ల్ల్ & 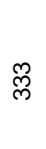 & 字 & $\bar{\varnothing}$ & ָั & $\bar{\aleph}$ & 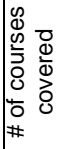 & to \\
\hline & Engineering Economics & & & & & & & & & & & & & & \\
\hline A & $\begin{array}{l}\text { Discounted cash flows (equivalence, PW, EAC, FW, IRR, loan } \\
\text { amortization) }\end{array}$ & & & $x$ & & & & & & & & & & $1 \mid$ & \\
\hline$B$ & $\begin{array}{l}\text { Types and breakdown of costs (fixed, variable, direct and indirect } \\
\text { labor, material capitalized) }\end{array}$ & & & $x$ & & & & & & & & & & 1 & \\
\hline C & $\begin{array}{l}\text { Analyses (benefit-cost, breakeven, minimum cost, overhead, risk, } \\
\text { incremental, life cycle) }\end{array}$ & & & $\mathrm{x}$ & & & & & & & & & & 11 & \\
\hline $\mathrm{D}$ & Accounting (financial statement and overhead cost allocation) & & & & & & & & & & & & & 01 & $x$ \\
\hline$E$ & Cost estimating & & & $x$ & & & & & & & & & & $1 \mid$ & \\
\hline $\mathrm{F}$ & Depreciation and taxes & & & $x$ & & & & & & & & & & $1 \mid$ & \\
\hline \multirow[t]{5}{*}{ G } & Capital budgeting & & & $x$ & & & & & & & & & & $1 \mid$ & \\
\hline & Multiple-attribute Decision Analysis & & & $x$ & $x$ & & & & & & & & & 2 & \\
\hline & Activity Based Costing & & & $\mathrm{x}$ & & & & $x$ & & & & & & $2 \mid$ & \\
\hline & Excel & & & $x$ & & & & & & & & & & $1 \mid$ & \\
\hline & Access & & & & & & & & & & & & & 0 & $x$ \\
\hline
\end{tabular}

Figure 4. Example of Topic Coverage Review

\section{Conclusions}

The authors have used FE exam topics as a tool in reviewing the industrial engineering curriculum at their respective schools. At one school the results was to maintain the current curriculum with minor changes. At the other school, a new course is being developed to address learning objectives in the areas of systems engineering and modeling. This type of periodic review can be a useful tool in an engineering department's effort to continuously improve.

\section{References}

Anderson, L. \& Krathwohl, D. A. (2001) Taxonomy for Learning, Teaching and Assessing: A Revision of Bloom's Taxonomy of Educational Objectives New York: Longman.

NAE, National Academy of Engineering, "The Engineer of 2020: Visions of Engineering in the New Century,” National Academies Press, ISBN-10: 0-309-09162-4, 2004.

NCEES website, http://www.ncees.org/About_NCEES.php, accessed 11/20/12. 